\title{
Discussion
}

\section{Question Mark Ear Deformity and a Modified Surgical Correction Method}

The authors present another type of correction for a relatively rare congenital ear deformity aptly named by Cosman et al. [1,2], the "question mark ear." The authors appropriately describe the defect as a deficiency of tissue at the junction of the ear lobe and helical rim and adjacent scapha (root of the helix), resulting in a partial cleft associated with varying degrees of protrusion of the ear itself.

In the single case described, the authors used a technique of elevating a posterior subcutaneous skin flap based laterally over a free graft of cartilage from the underlying concha to restore helical rim continuity. With this technique, the flap is rolled up to cover the grafted cartilage, and the skin flap donor site is closed, as depicted in their illustration. Unlike some other methods using either a Z plasty or multiple interdigitating flaps, the authors ${ }^{1}$ technique results in surgical scars on only the posterior surface of the ear, which is commendable

The authors address the problem of ear protrusion by closing the post auricular donor site. In my opinion, closing the donor site of the posterior surface of the ear will do nothing to decrease ear prominence permanently. Setting back the prominent ear should include either vertical scoring of the anterior surface at the junction of scapha and concha, as described by Stenstrom [5] (in my hands frequently unreliable), or a combination of scoring and sutures, as described by Mustarde [3] to recreate the often absent antihelix and set back the ear. If protrusion is attributable both to a failure of the antihelix to develop and to an enlarged or angulated concha, I prefer suturing the concha to the adjacent mastoid periosteum to assist in the setback of the upper ear [4].

Although there still is some mild deficiency of the helical rim at the reconstructed site, the patient has been afforded a very acceptable correction of the overall deformity.

Melvin Spira, M.D., D.D.S.

Department of Surgery

Baylor College of Medicine

6560 Fannin, Suite 800

Houston, TX, 77030, USA

email: mspira@bcm.tmc.edu

\section{References}

1. Cosman B, Bellin H, Crikelair GF: The question mark ear. Plast Reconstr Surg 46:454, 1970

2. Cosman B: The question mark ear: An unappreciated major anomaly of the auricle. Plast Reconstr Surg 73:572

3. Mustarde JC: The correction of prominent ears using simple mattress sutures. Br J plast Surg 16:170, 1963

4. Spira M, McCrea R, Gerow FJ, Hardy SB: Analysis and treatment of the protruding ear. Trans. Fourth Internatl. Congr. Plast. Surg. Exerpta Medical: Amsterdam, p. 1090, 1969

5. Stenstrom SJ: A natural technique for correction of congenitally prominent ears. Plast Reconstr Surg 32:509, 1963 